A CONSTRUÇÃO DIALÉTICA DE UMA CRIMINOLOGIA CRÍTICA PARAAS
FRONTEIRAS LATINOAMERICANAS

Fabiana Irala

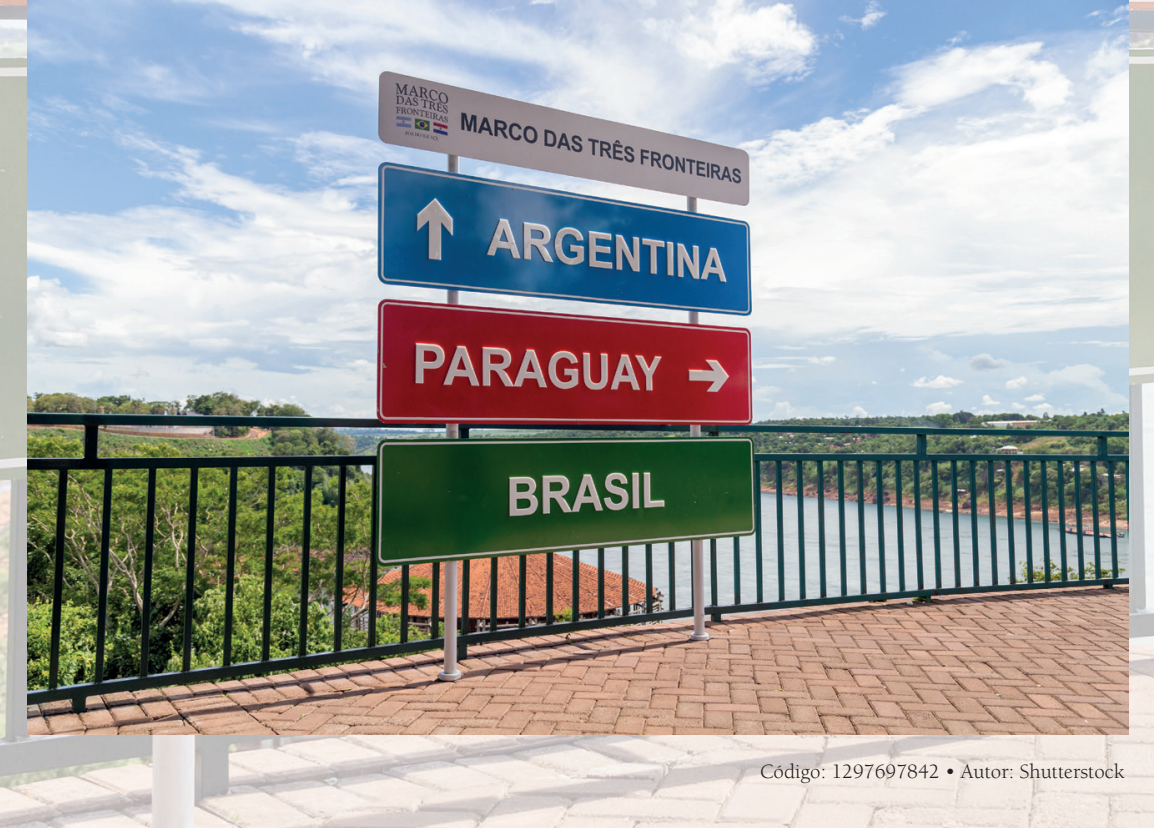





\title{
A CONSTRUÇÃO DIALÉTICA DE UMA CRIMINOLOGIA CRÍTICA PARA AS FRONTEIRAS LATINO-AMERICANAS
}

\author{
Fabiana Irala \\ Centro de Ensino Superior de Foz do Iguaçu, Brasil \\ Universidad de San Carlos, Guatemala
}

\section{Resumo}

Regiões de fronteira têm uma realidade particular marcada pela violência e pelos altos índices de criminalidade, com a presença maciça de polícias e entidades militares que buscam a repressão como controle social. Diante do avanço das organizações transnacionais, não é mais possível pensar na aplicação de teorias que desconsiderem a especificidade latino-americana. No que diz respeito à sua tradição criminológica, menciona-se que as políticas internas nacionais são elaboradas sobre a base do conhecimento produzido nos países centrais. A imitação de políticas centrais, frequentemente fora de contexto e utilizando metodologias dissonantes, tornam-nas fadadas ao insucesso. Assim, pontua-se que tal tema deve ser analisado sob a perspectiva da dependência histórica, edificada a partir do método dialético, considerando o processo de dominação cultural e a necessidade de insurgência da luta de classes contra o colonialismo. Nesse sentido, Maximo Sozzo trabalha a tradução dos modelos centrais, a importação cultural e a história do presente, buscando recobrar a ruptura criminológica das importações criminológicas com a descolonialização ideológica da criminologia. Sobre "fronteiras", o conceito tradicional abrange dois significados semânticos: fronteira-frontier, como front de batalha, utilizando a militarização como componente de repressão, e fronteira-borderland, como lugar de encontro e negociação. Portanto, percebe-se que métodos europeus de repressão em fronteiras não se adéquam à realidade latino-americana por aplicar, em sua origem, o duplo significado de fronteiras. Já nas fronteiras latino-americanas, considera-se apenas o contexto "frontier" - fronteiras como espaço facilitador da criminalidade transnacional; por isso, a inadequação do controle criminológico transfronteiriço atual e a necessidade do desenvolvimento de um método dialético próprio.

Palavras-chave: fronteiras latino-americanas, fronteiras, criminologia crítica, dialética, IEDCYT do CSIC, criminologia.

A autora: Fabiana Irala, doutoranda em Criminologia pela Universidade de São Paulo (USP), Largo do São Francisco. Professora de Direito Penal na Faculdade de Foz do Iguaçu (Fafig), Centro de Ensino Superior de Foz do Iguaçu (Cesufoz), Brasil, e de Políticas Públicas no Programa de Mestrado na Universidad de San Carlos, Guatemala. Correio eletrônico: fabiana_irala@yahoo.com.br

Recebido: 26 de julho de 2020; avaliado: 13 de setembro de 2020; aceito: 8 de outubro de 2020 


\title{
LA CONSTRUCCIÓN DIALÉCTICA DE UNA CRIMINOLOGÍA CRÍTICA PARA LAS FRONTERAS LATINOAMERICANAS
}

\author{
Fabiana Irala \\ Centro de Ensino Superior de Foz do Iguaçu, Brasil \\ Universidad de San Carlos, Guatemala
}

\begin{abstract}
Resumen
Las regiones fronterizas tienen una realidad particular enmarcada por la violencia y los altos índices de criminalidad, con la presencia masiva de policías y entidades militares que buscan la represión como control social. Ante el avance de las organizaciones trasnacionales, no es más posible pensar en la aplicación de teorías que no lleven en cuenta la especificidad latinoamericana. En cuanto a su tradición criminológica, se menciona que las políticas internas nacionales se elaboran sobre la base del conocimiento producido en los países centrales. La imitación de políticas centrales, con frecuencia descontextualizadas y con metodologías disonantes, las destinan al fracaso. Así, se puntúa que tal tema se debe analizar desde la perspectiva de la dependencia histórica, edificada con base en el método dialéctico, considerando el proceso de dominación cultural y la necesidad de insurgencia de la lucha de clases en contra del colonialismo. En este sentido, Máximo Sozzo trabaja la traducción de los modelos centrales, la importación cultural y la historia del presente, con el fin de recobrar la ruptura criminológica de las importaciones criminológicas con la descolonización ideológica de criminología. Acerca de "fronteras", el concepto tradicional abarca dos significados: frontera-frontier, como front de batalla, en que se utiliza la militarización como componente de represión, y frontera-borderland, como lugar de encuentro y negociación. Por lo tanto, se percibe que métodos europeos de represión en fronteras no se ajustan a la realidad latinoamericana por aplicar, en su origen, el doble significado de fronteras. Ya en las fronteras latinoamericanas, se considera apenas el contexto "frontier", fronteras como espacio facilitador de la criminalidad trasnacional; por eso, la inadecuación del control criminológico trasfronterizo actual y la necesidad del desarrollo de un método dialéctico propio.
\end{abstract}

Palabras clave: fronteras latinoamericanas, fronteras, criminología crítica, dialéctica, IEDCYT do CSIC, criminología.

La autora: Fabiana Irala, estudiante del doctorado en Criminología en la Universidade de São Paulo, Largo do São Francisco. Profesora de Derecho Penal en la Faculdade de Foz do Iguaçu, Centro de Ensino Superior de Foz do Iguaçu, Brasil, y de Políticas Públicas en el Programa de Maestría en la Universidad de San Carlos, Guatemala. Correo electrónico: fabiana_irala@yahoo.com.br

Recibido: 26 de julio de 2020; evaluado: 13 de septiembre de 2020; aceptado: 8 de octubre de 2020 


\title{
THE DIALECTICAL CONSTRUCTION OF A CRITICAL CRIMINOLOGY FOR LATIN AMERICAN BORDERS
}

\author{
FABIANA IraLA \\ Centro de Ensino Superior de Foz do Iguaçu, Brasil \\ Universidad de San Carlos, Guatemala
}

\begin{abstract}
Border regions have a particular reality framed by violence and high crime rates, with the massive presence of police and military entities that seek repression as social control. With the advance of transnational organizations, it is no longer possible to think about the application of theories that do not consider the specificities of Latin America. As for its criminological tradition, national domestic policies are elaborated on the basis of knowledge produced in central countries. The imitation of central policies, often decontextualized and with dissonant methodologies, destine them to failure. Thus, this issue must be analyzed from the perspective of historical dependence, built on the dialectical method, considering the process of cultural domination and the need for insurgency of the class struggle against colonialism. To this end, Maximo Sozzo works to translate the central models, cultural importation, and the history of the present, to recover the criminological break of criminological imports with the ideological decolonization of criminology. Regarding "borders," the traditional concept includes two meanings: border - frontier, as a battle front, in which militarization is used as a component of repression, and border-borderland, as a place of meeting and negotiation. Thus, once notes that European methods of border repression do not reflect the Latin American reality, as in its origin it applies the double meaning of the term border. Already in Latin American borders, the frontier context is barely considered, borders as a space to facilitate transnational criminality. Thus, current cross-border criminal control is inadequate, and it is necessary to develop a Latin American dialectical method.
\end{abstract}

Keywords: Latin American borders, borders, criminology, critical criminology, IEDCTY do CSIC.

Author: Fabiana Irala, doctoral student in criminology at the University of San Paulo, Largo do São Francisco. Professor of criminal law with the Iguaçu Law School, Center for Higher Education of Iguaçu, Brazil, and public policy in the Master's in Public Policy program at the University of San Carlos, Guatemala.Email: fabiana_irala@yahoo.com.br

Received July 26, 2020; evaluated September 13, 2020; accepted October 8, 2020 


\section{Introdução}

Fronteira terrestre é o limite territorial que demarca a linha divisória de soberania de cada país. Entre os 195 países mundiais, 134 apresentam ao menos uma tríplice fronteira. Quanto aos demais, tratam-se de países insulares (como o Japão), com uma única fronteira (como Portugal) ou com dupla fronteira não adjacente (como os Estados Unidos da América). Portanto, estudar fronteiras sob o viés da criminologia crítica, por si só, já é urgente e necessário.

Importante destacar que o termo "fronteira" não diz respeito apenas ao contexto territorial — elemento limítrofe de um Estado — mas também a outras dimensões securitárias relacionadas com questões econômicas, sociais, políticas e ideológicas nessas regiões. ${ }^{1}$

No conceito tradicional, é importante destacar duas abordagens de perspectivas semânticas: fronteira atrelada à noção de frontier e fronteira atrelada à noção de borderland. José Carlos dos Santos ensina que a noção de fronteira como frontier compreende o limite territorial como front de batalha, linha de frente, caracterizando-se por uma fronteira em movimento, em progressivo distanciamento do centro. Em razão disso, é um "espaço marcado por certa fluidez e criatividade, mas também por relações desiguais e pelo poder sem limites". Quanto à fronteira como borderland, destaca que é tratada pelos estudos pós-coloniais como espaço in-between, ou seja, lugar de encontro e negociação, não linear e fluida. ${ }^{2}$

Numa primeira análise, percebe-se que os meios de controle social intuem as regiões fronteiriças como uma "fronteira-frontier", linha de frente do combate à criminalidade transnacional. Para tanto, de fato tem utilizado a militarização como componente primordial na repressão. Por outro viés, os métodos de controle europeu pressupõem o duplo conceito de fronteiras: fronteiras-frontier e fronteiras-borderland, considerando a questão do fluxo migratório. Essa análise é necessária para o estudo das importações de modelos de controle social adotados nos Estados Unidos e na Europa.

Fernando José Ludwig. "Dinâmicas securitárias das fronteiras na América do Sul" em (Re)definições das fronteiras: velhos e novos paradigmas, ed. Fernando José Ludwig e Luciano Stremel Barros (Foz do Iguaçu: Editora Idesf, 2018), 39.

2 José Carlos dos Santos, "Uma leitura micro da Tríplice Fronteira Brasil, Paraguai e Argentina", http://www. snh2015.anpuh.org/resources/anais/39/1433683866_ARQUIVO_Textofinal2015.pdf (acesso outubro $15,2018$. 
Ainda que haja uma (possível) inadequação na importação dos modelos de controle social, deve-se abordar também sobre a criminologia crítica na América Latina, que inevitavelmente será avaliada sob a perspectiva da dependência histórica dos países latino-americanos (periféricos) com os países europeus (centrais).

Justamente em razão do contexto de exploração colonial, a América Latina apenas importou os modelos jurídicos europeus, o que evidentemente sufocou o desenvolvimento de teorias particulares. Nesse sentido, Lola Aniyar de Castro é mais incisiva ao afirmar que não existe uma criminologia latino-americana, mas uma transnacionalização do saber criminológico e, portanto, do controle social. ${ }^{3}$

A autora vai além: destaca que a criação da criminologia latino-americana deve ser edificada a partir da metodologia dialética, considerando o processo histórico de dominação cultural e a necessidade de insurgência da luta de classes contra o colonialismo.

Dessa forma, o desenvolvimento desta pesquisa visa contribuir, singelamente, para o avanço acerca do tema, de modo comprometido com o reconhecimento dos movimentos criminológicos e das singularidades das regiões de fronteira.

\section{Fronteiras latino-americanas e seus métodos de controle social}

Inicialmente, insta pontuar sobre a tradição criminológica da América Latina, verticalizando o estudo para a questão dos métodos de repressão adotados pelos órgãos de segurança pública nas regiões de fronteiras. Comumente, tais órgãos citam a especificidade fronteiriça para justificar determinadas ações controlatórias que potencialmente ferem direitos e garantias fundamentais, sob a égide da necessidade de "combate efetivo" aos crimes transnacionais, principalmente organizações criminosas, contrabando e descaminho, tráfico de drogas, de armas e de pessoas.

Com base na premissa de que fronteiras são meios geográficos facilitadores para a criminalidade (fronteira-frontier), estipula-se, então, um "inimigo visível", próximo e diário de populações vulneráveis, o que autorizaria o policiamento ostensivo e o uso das Forças Armadas. Nesse sentido, o principal argumento para a militarização

Lola Aniyar de Castro, Criminologia da libertação (Rio de Janeiro: Revan e Instituto Carioca de Criminologia, 2005), 20. 
das fronteiras tem sido o suposto "baixo efetivo de policiais" e a necessidade de ação contra os crimes transnacionais.

Segundo o livro Segurança pública nas fronteiras: diagnóstico socioeconômico e demográfico: estratégia nacional de segurança pública nas fronteiras (Enafron), "o efetivo policial por habitante é um indicador bastante utilizado para avaliar a presença do Estado na segurança da população". No entanto, o próprio estudo aponta que, "a partir da análise dos dados [...] é possível afirmar que a alocação do efetivo policial na Faixa de Fronteira obedece a uma lógica que tende privilegiar as cidades-gêmeas, ${ }^{4}$ o que nem sempre corresponde aos padrões de criminalidade violenta observados." ${ }^{5}$

Nesse sentido, o uso de prognósticos de riscos elaborados com base em estatísticas criminais já era alertado por Mauricio Dieter:

O processo de mensuração do risco de um criminoso tem por núcleo a atribuição de um valor numérico à suas diferentes características individuais e sociais para depois comparar essa informação com os dados de diferentes sujeitos já criminalizados, com o objetivo de ordená-los dentre desse padrão e decidir o que fazer com ele em função de sua posição relativa. ${ }^{6}$

Sob a argumento do "baixo efetivo", busca-se então militarizar as fronteiras latino-americanas com operações ostensivas que utilizam tanques e metralhadoras. Assim, o controle social é realizado por blitz, interceptações telefônicas, câmeras de vigilância e ações conjuntas entre Polícia Federal, Receita Federal, Polícia Rodoviária Federal e Forças Armadas. Nessa direção, destaca-se o modelo do Sistema Integrado de Monitoramento de Fronteira (Sisfron), tido como um modelo de vigilância, controle e atuação de fronteiras terrestres, que "contribuiria para a inviolabilidade do território nacional, para a redução dos problemas advindos da

4 O conceito de cidades-gêmeas foi definido pelo Ministério da Integração do Brasil em 2014 e vincula a terminologia aos municípios situados na linha de fronteira, seca ou fluvial, integrada ou não por obras de infraestrutura, que apresentem grande potencial de integração econômica e cultural. A definição só é válida para as cidades que tenham, individualmente, população superior a dois mil habitantes.

5 Segurança pública nas fronteiras, diagnóstico socioeconômico e demográfico: estratégia nacional de segurança pública nas fronteiras (Enafron), ed. Alex Jorge das Neves (Brasília: Ministério da Justiça e Cidadania, Secretaria Nacional de Segurança Pública, 2016), 468.

6 Mauricio Stegemann Dieter, A politica criminal atuarial: a criminologia do fim da história (Rio de Janeiro: Renavan, 2013), 20. 
região fronteiriça e para fortalecer a interoperabilidade, operações interagências e a cooperação regional."”

O projeto piloto do Sisfron emprega tecnologia de ponta, com sistemas de vigilância com equipamentos modernos de radares, softwares, sensores, comandos de controle fixos e móveis, armamentos, binóculos de visão termal, além de uma estrutura integrada de comunicação estratégica. A estrutura permite que as informações captadas pelos postos de vigilância cheguem em tempo real nos centros de operações, sejam interpretadas e usadas como suporte para a tomada de decisão.

Como nota-se, houve um processo de implementação do panoptismo nas fronteiras brasileiras, reformulado sob a égide militarista e com performance terrestre, marinha e aérea. Para a vigilância marinha, já é utilizado o modelo de policiamento do Núcleo Especial de Polícia Marítima da Polícia Federal, responsável pelo patrulhamento ostensivo. Quanto à vigilância aérea, destaca-se o modelo Vant (sigla para "veículo aéreo não tripulado"), equipamento de fabricação israelense dotado de câmeras de vigilância, com autonomia de voo para mais de 20 horas.

A premissa de que regiões de fronteiras são territórios facilitadores de criminalidade permite ações de controle social baseadas em formulações de teorias do conflito, especialmente do neorretribucionismo. Evidencia-se tal afirmativa nas Operações de Garantia da Lei e da Ordem brasileiras, que, como bem denota o nome escolhido, tem como premissa a intolerância à prática de quaisquer delitos. Em análise, percebe-se que essa ofensiva militar é baseada em modelos americanos e europeus de "combate à criminalidade fronteiriça", obviamente sem considerar e ponderar sobre as diferenças geopolíticas existentes.

Já bem afirmava Roberto Bergalli que o desenvolvimento cultural dos países latinoamericanos sempre teve uma relação de dependência com ideias estrangeiras. ${ }^{8}$ No mesmo sentido, Rosa del Olmo já questionava a "importação do saber de países

$7 \quad$ Nesse sentido, a região da Tríplice Fronteira entre Brasil, Argentina e Paraguai. Exército Brasileiro, Departamento de Ciência e Tecnologia, "Termo de Fomento a ser firmado entre o Exército Brasileiro e a Fundação Parque Tecnológico de Itaipu. Exército Brasileiro. http://www.dct.eb.mil.br/index.php/termo-de-fomento-a-ser-firmado-entre-o-exercito-brasileiro-e-a-fundacao-parque-tecnologico-de-itaipu-br/35-programas-e-parceiros/97-sisfron (acesso outubro 4, 2019).

8 Roberto Bergalli, "Una intervención equidistante pero en favor de la sociología del control penal", Doctrina Penal 36 (outubro, 1986):78. 
centrais", mediante a importação de modelos (de controle social) incompatíveis com nossa realidade periférica. ${ }^{9}$

Por que tais importações de modelos de controle social baseados nas fronteiras americanas e europeias não surtem os efeitos esperados na América Latina? No artigo "Violência, contrabando e a ausência de paz nas regiões de fronteira: uma visão crítica", o professor Fernando José Ludwig declara sobre o problema latino-americano:

No que se refere à institucionalização da violência nas regiões de fronteira, devemos também nos atentar ao fato do chamado spill over effect, em que há de facto uma soberania exercida por aqueles que controlam essa indústria, "soberania do tráfico", reduzindo assim o poder Estatal em relação ao uso legítimo da força dentro de seu território nacional. A primeira, e talvez a mais evidente, consequência desta realidade, é a corrupção dos entes públicos responsáveis justamente pelo combate a esta prática ilegal. ${ }^{10}$

Dessa forma, entende-se que o problema de segurança pública nas fronteiras latinoamericanas passa pela questão do tráfico de drogas, armas, contrabando, descaminho e agrotóxicos, crimes que gerariam violência social. Por isso, a justificativa de ações conjuntas de órgãos de repressão estatal.

Quanto às fronteiras europeias, Licínia Simão (professora de Relações Internacionais da Faculdade de Economia da Universidade de Coimbra) denuncia que há dinâmicas peculiares que marcam as fronteiras da União Europeia. A primeira envolve a questão da migração ilegal. A Comissão Europeia apresentou, em 2011, uma proposta de abordagem global à migração e à mobilidade que, entre suas medidas, está a criação da Agência Europeia para a Gestão da Cooperação Operacional nas Fronteiras Externas dos Estados-Membros da União Europeia (Frontex). Assim, a Frontex agiria como uma agência de práticas securitizadoras ${ }^{11}$ das políticas de asilo da União Europeia. Militarizam-se as fronteiras europeias e se combatem imigrantes ilegais pelos mesmos sistemas e meios do combate ao terrorismo e ao crime organizado.

9 Rosa del Olmo, A América Latina e sua criminologia (Rio de Janeiro: Revan, 2004), pg. 29.

10 Fernando José Ludwig, "Violência, contrabando e ausência de paz nas regiões de fronteira: uma visão crítica" em (Re)definições das fronteiras: visões interdisciplinares, ed. Fernando José Ludwig e Luciano Stremel Barros (Curitiba: Juruá, 2016), p.28

11 Os processos de securitização podem ser definidos como processos pelos quais os atores estatais transformam sujeitos em questões de segurança, que justificam a aplicação de medidas extraordinárias em nome da segurança. 
Em segundo, o setor de desenvolvimento tecnológico de gestão fronteiriça é visto por empresas privadas de segurança como um mercado lucrativo, com estimativa de movimentação financeira de USD \$56.520.000,00 (cinquenta e seis milhões, quinhentos e vinte mil dólares) em 2022. Esse processo é apelidado como a criação de um "mercado global de tecnologias de repressão". ${ }^{12}$

Quanto às fronteiras americanas, a problematização envolve a barreira terrestre com o México, tão somente. Cite-se a construção de 376 quilômetros de muro nos estados da Califórnia, do Novo México e do Arizona e no México, sob o argumento da proibição de migrantes ilegais, drogas, traficantes de seres humanos e organizações criminosas. Segundo Rafael Francisco França, as autoridades estadunidenses entendem que o governo mexicano é fraco ou até mesmo corrupto demais para fazer frente aos cartéis que dominam o narcotráfico entre os dois países. ${ }^{13}$

Apesar dessa (pretensa) preocupação com o narcotráfico, indica-se que a verdadeira intenção da vigilância envolve a questão da migração ilegal mexicana, naquilo que Zaffaroni já bem explicava como "exercício do poder dirigido à contenção de grupos determinados e não à repressão do delito, num grau de arbitrariedade seletiva dirigida". ${ }^{14}$ Como demonstração, cite-se a criação dos "xerifes virtuais" que patrulham a fronteira entre o México e o Texas por meio do Programa de Monitoramento Virtual da Fronteira do Texas, pelo site Blueservo.net. O programa já custou 4 milhões de dólares e convida civis para visitarem o site e observarem transmissões ao vivo de 21 câmeras de vigilância instaladas ao longo da fronteira. ${ }^{15}$

Em tempo, é necessário realizar uma observação: nos estudos envolvendo o tema "fronteiras americanas", não foi encontrada qualquer justificativa de controle em razão do terrorismo, supostamente a principal preocupação de segurança pública americana. Isso pode ser considerado, de fato, uma reafirmação à citação de Zaffaroni: "contenção de grupos determinados e não repressão do delito" — direito penal do inimigo voltado aos migrantes mexicanos. Como bem adverte Peter Andreas, "os

12 Licínia Simão, "Os impactos da securitização e militarização da fronteira externa da União Europeia" em (Re)definições das fronteiras: visões interdisciplinares, ed. Fernando José Ludwig e Luciano Stremel Barros (Foz do Iguaçu: Editora Idesf, 2019), p. 49.

13 Rafael Francisco França, Controle de fronteiras no Brasil (São Paulo: Estante Acadêmica, 2018), 114.

14 Eugenio Raúl Zaffaroni, Em busca das penas perdidas: a perda da legitimidade do sistema penal, 5. ed. (Rio de Janeiro: Revan, 2018, p. 53

15 Claire Prentice, "Xerifes virtuais' patrulham fronteira do Texas com o México", BBC News, 27 de dezembro de 2009. https://www.bbc.com/portuguese/noticias/2009/12/091227_fronteira_patrulha_virtual_rw (acesso outubro 13, 2019). 
responsáveis pelos ataques ao Pentágono e às Torres Gêmeas não ingressaram no território americano apoiados por coiotes ou cruzando a fronteira com o Canadá."16

Assim sendo, volta-se à problemática inicial de fronteiras latino-americanas vigiadas, controladas e militarizadas sob a reprodução de modelos importados. Em uma rápida observação, verifica-se que as justificativas são diferenciadas: na América Latina, combate à criminalidade de drogas, armas e contrabando; na Europa e Estados Unidos, combate à migração ilegal.

\section{Premissas para desenvolvimento de uma criminologia crítica para as fronteiras latino-americanas}

Do conceito tradicional de fronteira, entende-se como o limite territorial que demarca a linha divisória de soberania de cada país. Contudo, com a globalização, deve-se considerar que essas zonas limítrofes são dinâmicas, com transações comerciais e fluxo de pessoas.

A fronteira tanto separa países quanto os põe em contato. Ademais, nessas circunstâncias, está a presença do Estado, que, a seu modo, deve estar reiteradamente instituindo o "espírito nacional". Acrescenta-se ainda a estes elementos de alteridades o simpl,,,,es ato de cruzar a fronteira, que é o elemento que define o outro como estrangeiro, forasteiro. Converter um ambiente fronteiriço em algo fluido, em que o espírito de nacionalidade seja enfraquecido, não justifica o conceito de que a fronteira, enquanto limite, seja apenas uma abstração. ${ }^{17}$

Como citado, a consideração das fronteiras latino-americanas apenas sob o viés "frontier" gera a visão dessas regiões como territórios marcados por violência e altos índices de criminalidade. Portanto, "se há guerra", aceita-se então a presença maciça de polícias e entidades militares que buscam a forte repressão como forma de controle social. Quanto à criminologia crítica latino-americana, percebe-se que há uma completa lacuna sobre o assunto "fronteiras". Nada se tem criado sobre o que permite a continuação do processo de decolonialização com a importação de tais modelos centrais inadequados à realidade periférica.

Peter Andreas, "Redrawing the line: borders and security in the twenty-first century", Internacional Security 28, núm.2 (outono 2003):154.

17 José Rita Martins Lara, "Segurança nas fronteiras: uma utopia?" em (Re)definições de fronteiras: visões interdisciplinares, ed. Fernando José Ludwig e Luciano Stremel Barros (Curitiba: Juruá, 2016), p. 57. 
Nesse sentido, Zaffaroni destaca a deslegitimação do direito penal mediante a perpetuação do poder e domínio de classes por meio da violência dos órgãos que compõem o sistema. No entanto, há uma distinção conceitual entre violência e criminalização. Não há qualquer dúvida que uma determinada ação possa ser classificada como uma violência, mas a prática da criminalização é um aprimoramento e uma sofisticação dessa violência.

No direito penal subterrâneo, o processo de criminalização dos indivíduos é engendrado pelo estereótipo do delinquente como membro de classe desfavorecida e de sua conservação na marginalidade social.

No sentido de criminalização dos indivíduos latino-americanos, Rosa Del Olmo narra que a construção do sistema punitivo marginal passa obrigatoriamente pela criminologia positivista, que num primeiro momento elegeu o indígena e o negro como "criminosos natos". ${ }^{18}$ Em pleno 2019, isso ainda faz total sentido, já que nas regiões de fronteiras são considerados criminosos os indivíduos que compõem as sociedades marginais, compostas, em sua maioria, de descendentes indígenas.

Abordando sobre o interacionismo simbólico, Alessandro Baratta pontua: "os criminólogos tradicionais examinam problemas do tipo 'quem é o criminoso?', 'como se torna desviante?', 'com que meios se pode exercer controle sobre o criminoso?' Ao contrário, os interacionistas, se perguntam: 'quem é definido como desviante?', 'que efeito decorre desta definição sobre o indivíduo?', 'quem define quem'?"19

Nesse processo de seletividade e vulnerabilidade, percebe-se que as agências repressivas acabam selecionando aqueles que circulam pelos espaços delimitados como "áreas de guerra" com figurino social dos delinquentes. Uma vez marginalizados, perpetuam o ciclo da criminalização:

A inevitável seletividade operacional da criminalização secundária [...] provoca uma distribuição seletiva em forma de epidemia, que atinge apenas aqueles que tem baixas defesas perante o poder punitivo, aqueles que se tornam mais vulneráveis à criminalização secundária porque: a) suas características pessoais se enquadram nos estereótipos criminais; b) sua educação só lhes permite realizar ações ilícitas toscas e, por consequência, de fácil detecção e c) porque

Olmo, A América Latina e sua criminologia, 43.

19 Alessandro Baratta. Criminologia crítica e crítica do direito penal: introdução à sociologia do direito penal, 6a ed. (Rio de Janeiro: Revan, 2013), 88. 
a etiquetagem suscita a assunção do papel correspondente ao estereótipo, com o qual seu comportamento acaba correspondendo ao mesmo (a profecia que se auto-realiza). ${ }^{20}$ (destaque não previsto no original)

Maximo Sozzo já discorria que os conflitos do processo de colonialização não são de mero interesse histórico. O impacto das expropriações do passado — violência nas fronteiras, segregação e controles administrativos autocráticos ancorados em supostas leis de "proteção" e "bem-estar", esforços conjuntos de dizimação cultural (desmembramento de famílias e remoção de crianças), alcançam o presente, afetando negativamente a população local. ${ }^{21}$

Portanto, a violência nas fronteiras pode ser vista como uma decorrência histórica da colonialização, e não como uma decorrência imperativa da (suposta) criminalidade de fronteira. Por isso, é urgente uma emancipação teórica e prática que reflita a problemática das tríplices fronteiras e o controle social, não se limitando à questão territorial.

\section{Considerações finais}

O tema "fronteiras" tem despertado a atenção das agências públicas e da academia em razão de dois problemas principais suscitados: fluxo migratório e criminalidade internacional. O fato de algumas cidades serem limítrofes com outros países faz com que sejam palco da chamada "criminologia de fronteira".

Nesse cenário, visualiza-se que os métodos de controle social são usualmente importados e copiados dos modelos europeu (como o modelo de polícia Frontex) e americano (como o escritório de inteligência e vigilância ostensiva Fusion Centers), mas sem as devidas considerações sobre as especificidades latino-americanas.

Com base em Lola Aniyuar e Rosa Del Omo, compreende-se que os métodos de combate à criminalidade de fronteira são inadequados, devendo ser adequados ao método dialético, que romperá com o processo de perpetuação de dominação social e cultural.

20 Eugenio Raul Zaffaroni, Nilo Batista, Alejandro Alagia e Alejandro Stokar, Direito penal brasileiro: primeiro volume, 4. ed. (Rio de Janeiro: Revan, 2017), 47.

21 Máximo Sozzo, "Tradutore traditore': traducción, importación cultural e historia del presente de la criminología en América Latina", Cuaderno de doctrina y jurisprudencia penal 7, núm. 13 (2002):353. 


\section{Referências}

Andreas, Peter. "Redrawing the line: Borders and security in the twenty-first century". Internacional Security 28, núm.2 (outono 2003): 37.

Baratta, Alessandro. Criminologia crítica e crítica do direito penal: introdução à sociologia do direito penal. 6. ed. Rio de Janeiro: Revan, 2013.

Bergalli, Roberto. "Una intervención equidistante pero en favor de la sociología del control penal". Doctrina Penal 36, (1986): 78.

Bordignon, Fabiano. "Ultrapassando fronteiras: cooperação policial internacional e o exemplo do comando tripartite na Tríplice Fronteira Argentina, Brasil e Paraguai" em (Re)definições das fronteiras — visões interdisciplinares, editado por Fernando José Ludwig e Luciano Stremel Barros, 25-57. Curitiba: Juruá, 2017.

Cardin, Eric Gustavo. "Trabalho e práticas de contrabando na fronteira do Brasil com o Paraguai". Geopolítica(s): Revista de estúdios sobre espacio y poder 3, num.2 (2012): 208. https://revistas.ucm.es/index.php/GEOP/article/ (acesso novembro 10, 2018).

Castro, Lola Aniyar de. Criminologia da libertação. Rio de Janeiro: Revan: Instituto Carioca de Criminologia, 2005.

Dieter, Mauricio Stegemann. A política criminal atuarial: a criminologia do fim da história. Rio de Janeiro: Renavan, 2013.

Elbert, Carlos Alberto. Criminologia latino-americana: teoria e propostas sobre o controle social do terceiro milênio. vol. 2. São Paulo: LTr, 2010.

Focault, Michel. Vigiar e punir: nascimento da prisão. 42. ed. Petrópolis: Vozes, 2014.

França, Rafael Francisco. Controle de fronteiras no Brasil. São Paulo: Estante Acadêmica. 2018.

Jakobs, Günther. Direito penal do inimigo: noções e críticas. 4. ed. Porto Alegre: Livraria do Advogado, 2009.

Konig, Mauri. O Brasil oculto: crime das fronteiras obscuras aos paraísos à beira-mar. Curitiba: Compactos, 2013.

Lara, José Rita Martins. "Segurança nas fronteiras: uma utopia?" em (Re)definições de fronteiras: visões interdisciplinares, editado por Fernando José Ludwig e Luciano Stremel Barros, 58-70. Curitiba: Juruá, 2016.

Ludwig, Fernando José. "Violência, contrabando e ausência de paz nas regiões de fronteira: uma visão crítica”, em (Re)definições das fronteiras: visões interdisciplinares, editado por José Ludwig e Luciano Stremel Barros, 17-30. Curitiba: Juruá, 2016.

Ludwig, Fernando José. "Dinâmicas securitárias das fronteiras na América do Sul", em (Re) definições das fronteiras: velhos e novos paradigmas, editado por Fernando José Ludwig e Luciano Stremel Barros, 17-34. Foz do Iguaçu: Idesf, 2018.

Batista, Vera Malaguti. O medo na cidade do Rio de Janeiro: dois tempos de uma história. Rio de Janeiro: Revan, 2003. 
Monet, Jean-Claude. Polícias e sociedades na Europa. São Paulo: Editora Universidade de São Paulo, 2001.

Olmo, Rosa del. A América Latina e sua criminologia. Rio de Janeiro: Revan, 2004.

Santos, José Carlos dos. "Uma leitura micro da Tríplice Fronteira Brasil, Paraguai e Argentina". Artigo apresentado em XXVIII Simpósio Nacional de História, Florianópolis (SC), de 27 a 31 de julho, 2015. http://www.snh2015.anpuh.org/resources/ anais/39/1433683866_ARQUIVO_Textofinal2015.pdf (acesso em 02/12/2019).

Santos, Juarez Cirino dos. A criminologia radical. 3. ed. Curitiba: ICPC e Lúmen Iuris, 2008. Segurança pública nas fronteiras, diagnóstico socioeconômico e demográfico: estratégia nacional de segurança pública nas fronteiras (Enafron), ed. Alex Jorge das Neves (Brasília: Ministério da Justiça e Cidadania, Secretaria Nacional de Segurança Pública, 2016), 468.

Shecaria, Sérgio Salomão. Criminologia. 7. ed. São Paulo: Thomson Reuters Brasil, 2018. Simão, Licínia. "Os impactos da securitização e militarização da fronteira externa da União Europeia”, em (Re)definições das fronteiras: visões interdisciplinares, editado por José Ludwig e Luciano Stremel Barros, 43-56. Curitiba: Juruá, 2016.

Exército Brasileiro. Departamento de Ciência e Tecnologia. "Integrando capacidades na vigilância e na atuação em nossas fronteiras". http://www.dct.eb.mil.br/index. php/termo-de-fomento-a-ser-firmado-entre-o-exercito-brasileiro-e-a-fundacaoparque-tecnologico-de-itaipu-br/35-programas-e-parceiros/97-sisfron (acesso outubro 4, 2019).

Máximo Sozzo, “Tradutore traditore': traducción, importación cultural e historia del presente de la criminología en América Latina". Cuaderno de doctrina y jurisprudencia penal 7, núm. 13 (2002):353.

Teresi, Verônica Maria. Tráfico de pessoas: reflexões em áreas de fronteira. Foz do Iguaçu: Editora Idesf, 2019.

Prentice, Claire, "Xerifes virtuais' patrulham fronteira do Texas com o México", BBC News. 27 de dezembro, 2009. https://www.bbc.com/portuguese/noticias/2009/12/091227_fronteira_patrulha_virtual_rw (acesso outubro 13, 2019).

Zaffaroni, Raúl Eugenio. Criminología: aproximación desde un margen. Bogotá: Temis, 1988. Zaffaroni, Eugenio Raul, Nilo Batista, Alejandro Alagia e Alejandro Stokar. Direito penal brasileiro: primeiro volume. 4. ed. Rio de Janeiro: Revan, 2017.

Zaffaroni, Eugenio Raúl. Em busca das penas perdidas: a perda da legitimidade do sistema penal. 5. ed. Rio de Janeiro: Revan, 2018. 